\title{
Prevalence and risk factors of burnout among Lebanese community pharmacists in the era of COVID-19 pandemic: Results from the first national cross- sectional survey
}

Dalal Youssef ( $\nabla$ dalalyoussef.esu@gmail.com )

Ministry of Public Health Lebanon https://orcid.org/0000-0003-3085-6849

Janet Youssef

Al zahraa hospital university medical center

\section{Linda Abou-Abbas}

Ministry of Public Health Lebanon

Hamad Hassan

Ministry of Public Health Lebanon

\section{Research Article}

Keywords: Burnout, community pharmacists, COVID-19, prevalence, risk factors, Lebanon

Posted Date: October 22nd, 2021

DOI: https://doi.org/10.21203/rs.3.rs-1005468/v1

License: (c) (i) This work is licensed under a Creative Commons Attribution 4.0 International License. Read Full License

Version of Record: A version of this preprint was published at Journal of Pharmaceutical Policy and Practice on December 1st, 2021. See the published version at https://doi.org/10.1186/s40545-021-00393-w. 


\section{Abstract}

Background: The increasing occupational challenges inflicted on community pharmacists (CPs) in the wake of COVID-19 lays this valuable human resource at increased risk of burnout.

Objectives: This study aimed to assess the prevalence of burnout among Lebanese CPs in the era of COVID-19 and to identify its associated factors.

Methods: A web-based cross-sectional study was conducted among Lebanese CPs between the $1^{\text {st }}$ of February and the end of March 2021 using a snowball sampling technique. Data was collected using an anonymous Arabic self-administered questionnaire that includes information on socio-demographic characteristics, exposure and work-related variables, and two scales: the Copenhagen burnout inventory (CBI) which includes personal, workrelated, and patient-related dimensions of burnout, and the COVID-19 threat perception scale. To evaluate the prevalence of burnout, $\mathrm{CBI}$ scale cut-off score of 50 was used. Bivariate and multivariable logistic regression analyses were used to identify the factors associated with burnout among CPs.

Results: Burnout was detected among $81.9 \%$ of surveyed CPs, where $61 \%$ had a moderate burnout and $20.9 \%$ had a high level of burnout. Client burnout (CB) ranked first among other burnout aspects (89.7\%) followed by personal burnout (77.8\%) and work-related burnout (76.8\%). Younger age, female gender, being staff pharmacist, working in pharmacy operating around the clock and working more than 40 hours per week were associated with higher level of burnout. Similarly, suffering from comorbidity, having a dependent child or living a family member with comorbidities, experiencing sleep disturbance and high perception of COVID-19 threat were also associated with higher burnout. However, being married, having large professional experience, having high socioeconomic situation, accepting the risk of dealing with COVID-19 cases and having previous history of COVID-19 were negatively associated to burnout.

Conclusion: Burnout hits $81.9 \%$ of the Lebanese CPs. This alarming prevalence called health authorities to take prompt and warranted measures based on the factors associated with this syndrome unearthed in this study, to prevent burnout and mitigate among CPs in order to support resiliency in the profession.

\section{Background}

Similar to other demanding jobs, burnout syndrome is, unfortunately, affecting all disciplines of the healthcare workforce, and community-pharmacy personnel is no exception [1-4]. The role of community pharmacists (CPs) has expanded in the past two decades with increasingly autonomous, direct patient care roles across all settings such as immunizations and medication therapy management [5]. However, this pivot from product-based care to service-based care won't happen overnight and CPs were confronted by several challenges when chasing to achieve the healthcare provider status [6]. This has added extra layers of intricacy such as juggling the delicate balance of incorporating clinical services into traditional dispensing environments while being forced into performance metrics $[7,8]$.

By focusing squarely on the patient and delivering medical services, CPs faced performance metrics, such as dispensing medications and immunization quotas, along with the pressure of counseling patients, calling physicians, and coordinating with suppliers and pharmaceutical companies $[9,10]$. Furthermore, overwrought performance goals that create unbearable stress, difficult clients' behavior, the complexity of workflow, and 
dismally low compensation could also contribute to the increase of burnout among CPs [11-14]. Of note, stressors confronted by CPs mirror those of physicians, including an ineffective work environment, the burden of nonclinical and administrative duties, and excessive workloads combined with a dearth of resources required to realize desired goals and upshots [15]. On other hand, the negative consequences of CPs ' burnout are similar to what found among other healthcare workers (HCWs) and could affect patient care, the healthcare system, and the provider health such as lower care quality, increased medical errors, dwindled patient or client satisfaction, reducing provider productivity, and increasing provider turnover [16]. Finally, burnout can lead to poor self-care, substance abuse, depression, and suicidal ideation [17-20].

However, burnout is not deeply explored in the landscape of the CPs population. Some studies reported that burnout is prevalent among pharmacists. A systematic review appraised that the prevalence of overall burnout among pharmacists ranged from $52 \%$ to $61 \%$ [21]. Another study conducted with the assistance of the American Pharmacists Association (APhA) before the pandemic, has estimated that $75 \%$ of the study participants suffered from burnout [22]. Given the large heterogeneity in the role and responsibilities of CPs within health systems and across practice settings [23], hence it is essential when assessing CPs burnout to take into consideration differences among pharmacy practice settings that could contribute to differing levels of burnout.

Since the onset of COVID-19, increased demand for medical services has strained worldwide the health care systems to their limits [24]. Subsequently, the majority of non-urgent operations and medical services in health facilities were canceled or suspended to allow the healthcare system to manage the soar of severe cases of COVID-19. As result, the public turned to community pharmacists (CPs) since they remain the most accessible face-to-face primary healthcare provider during a period where in-person healthcare consultations are reserved [25]. Hence, the enormous potential role of CPs in alleviating the burden imposed on the shoulder of other healthcare providers was emphasized during these unprecedented times. In addition, the pivot from medicinecentered to patient-centered care was hastened by the pandemic. Despite that continuing face-to-face care might provide an opportunity for education and counseling for patients, it also carried a risk of exposure to COVID19 [26]. In addition, working conditions in the community-pharmacy setting have been hastily changing and increased responsibilities making the pharmacy service an industry prone to disturbance [27]. Some countries have recognized these settings as an ideal access point for patients and allowed CPs to run COVID-19 testing along with COVID-19 vaccination services. These inflicted duties on the shoulder of community-pharmacy personnel in the wake of COVID-19 have created ideal conditions to place and to leave this valuable human resource at increased risk of burnout in the aftermath. Several studies described the psychological impacts of the COVID-19 pandemic on healthcare workers [28] but CPs are rarely included in such studies despite their publicfacing roles during pandemics.

In regards to Lebanon, this small Middle Eastern country is stranded amidst a mixture of crises, blending the COVID-19 pandemic with a terrible economic downfall and political turmoil [29]. After about a year of working in such an environment combining financial hardship to the COVID-19 pandemic, the vital resource represented by the healthcare workforce is foundering. CPs are front-line HCWs playing a major role in medication management during the pandemic [1]. The novel, unique challenges squarely associated with the COVID-19 are aggravating an already stressful work environment in community pharmacy [27]. Besides, the economic collapse and the steep loss of the value of the Lebanese currency combined with the inflation of the prices of the medicines and the imposed lockdown, escalate concerns among the Lebanese population towards an imminent shortage in medicines in the Lebanese market. Turned into panic mode, the Lebanese population experienced an 
unprecedented race to purchase medicines by patients. These stressors such as the soaring demand for medicines, limited supply chain, the financial crisis, the threat of COVID-19, and the increased responsibilities created ideal conditions to leave burned-out pharmacy personnel in the aftermath. Furthermore, precautions measures implemented in the pharmacy setting, managing crowding, and social distancing have been also shown to have the potential to increase work-related stress $[30,31]$. With healthcare workers reporting psychological impacts from the COVID-19 pandemic, burnout syndrome has not been assessed among CPs whereas these professionals are exposed to patients' demands and difficulties every day. Therefore, it is of great interest to assess the extent of burnout among CPs specifically in the context of double hit using a validated tool and to identify its associated factors to orient interventions to be adopted by health authorities and pharmacy professional organizations to mitigate and prevent burnout. This study aimed to assess the prevalence of burnout among Lebanese CPs using the Copenhagen Burnout Inventory and to identify its associated factors.

\section{Methods}

\section{Study design and population:}

A national web-based cross-sectional study was conducted among Lebanese community pharmacists over 2 months from the $1^{\text {st }}$ of February 2021 till the end of March 2021. In compliance with social distancing restrictions, participants were selected using a snowball sampling technique. Participants were identified via the list of registered CPs provided by the Lebanese order of pharmacists (OPL) and were electronically invited to participate. Before their enrollment in the study, CPs were contacted via phone call and notified about the survey and its purpose. Upon their agreement to participate, and based on their preference of the way to receive the link of the study, an online questionnaire using a Google form was sent to them via emails or WhatsApp. They were also invited if possible to disseminate the link of the survey among their colleagues. The link of the study included a brief explanation of the study purpose and electronic informed consent.

All CPs of either gender or profile (owner, manager, or staff pharmacist) working in pharmacy setting at the time of the survey, who had access to the internet and who agreed to participate in the study were eligible for participation. These professionals were defined as the pharmacy team. Exclusion criteria were defined as follows: clinical pharmacists, retired community pharmacists, those who were out of the country at the time of the survey, trainees and pharmacy students or other professionals (e.g., dietician, beautician), and other pharmacies staff as well as those not practicing actually. Pharmacists who were unreachable due to a change in their contact information during the time of the survey and those who refused to give informed consent were also excluded from the study. There was no age limitation. All methods were performed following the relevant guidelines and regulations such as the STROBE (Strengthening the Reporting of Observational Studies in Epidemiology) guidelines for reporting observational studies [32]. Since the study has no foreseeable risks, written consent was obtained in an electronic format. Participants haven't received any compensation for their participation in the study.

\section{Ethical consideration}

Participation in this survey was voluntary and participants were allowed to leave the study at any time. Electronic informed consent was obtained for each participant. All information was gathered anonymously and handled 
confidentially. The study design assured adequate protection of study participants. None of the survey questions asked for information that could harm the participant in any way.

\section{Sample size calculation}

The digital Raosoft sample size calculator was used to calculate the sample size of the study, based on a total population size of 4185 community pharmacies registered with OPL, a 95\% confidence level and an absolute error of $5 \%$, a minimal sample of 352 pharmacists was required.

\section{Instrumentation:}

A 58-items questionnaire was developed by the authors to assess the study objectives and to cover important aspects of burnout in the Arabic and the English languages through an online platform via Google forms. The utilized scales used were translated into Arabic following the guidelines for forward and backward translation, except for the CBI-A already validated among Lebanese HCWs and available in the Arabic language (Youssef et al. submitted) and the HADS scale validated. A consensus was used to resolve inconsistencies between the original and translated versions. A pilot survey was also conducted among 20 community pharmacists and some reformulations for some questions were made throughout its course. Of note, the answers to the pilot survey were excluded from the final data of this study. The finalized anonymous, self-administered questionnaire was comprehensible and took 9 to 12 minutes to complete. The questionnaire included mainly closed-ended questions. It consisted of three sections: (a) sociodemographic characteristics, (b) occupational and exposure to COVID-19 variables, and (c) the measurements.

The first section collected sociodemographic data of the participants, including gender, age, marital status, profile, residency, education level, and health status. It also included questions about the history of medical illnesses, the health status of people living with the participant, and the presence of an elderly or dependent child at home. The second section covered the topic of occupational conditions and exposure to COVID-19. Physicians were queried to answer on whether they have worked in the frontline, dealing with COVID-19 patients, (b) been tested for COVID9 (c) been diagnosed as COVID19 case, (d) had a family member relative or colleague infected by COVID-19. Each of these variables was answered on a yes or no basis.

The third section consisted of 2 scales to objectively assess COVID-19 threat perception, and burnout among the participants.

\section{1-The perceived threat and altruistic acceptance of risk questionnaire:}

This tool was developed by Chong et al to assess the risk perception of COVID-19 among HCWs, the perceived threat questionnaire [33]. It consisted of 10 items where nine of these items described HCWs' perception toward COVID-19 threat and one item related to altruistic acceptance of COVID-19 risk. Ratings were given based on a five-point Likert scale ( 1 =strongly disagree, 2 = disagree, 3 = neutral, 4=agree, $5=$ strongly angry). Responses were dichotomized into positive responses 'agree' or 'strongly agree', while 'strongly disagree', 'disagree', and 'not sure' were considered negative. The Cronbach alpha of this scale was equal to 0.703 .

\section{2- The Arabic version of Copenhagen Burnout scale A-CBI:}


The 19-items CBI version validated among CPs (Youssef et al.) was used in the current study to evaluate the three aspects of burnout: personal-related (6 items), work-related (7 items), and client-related (6 items) burnout [34]. In our study, the Cronbach's alpha of this scale was equal to 0.787 . The $\mathrm{CBI}$ items were mixed with questions on other topics in order to avoid stereotyped response patterns. CPs were asked to rate how often they felt exhausted on a five-point Likert scale as follows:( $0=$ never, $25=$ Seldom, $0=$ Sometimes, $75=$ Often, $100=$ Always). Other questions were also ranked on a five-point Likert scale but using different answers (to a very high degree, to a high degree, somewhat, to a low degree, to a very low degree). The coding was reversed for item 7 asking about having enough energy for family and friends during leisure time as a positive response was an indicator of a low burnout. The mean item was calculated for each subscale. A cut-off of 50 was used to assess the prevalence of burnout among CPs. The score was dichotomized as follows: a score equal or more than 50 is considered a high burnout level whereas a score less than 50 signify a low burnout level. Of note, when assessing the prevalence of burnout we split the high burnout level in two levels: a score 50-74: moderate, $>75$ high (Ref) in order to have more explanatory information [35].

\section{Statistical analysis:}

The generated data on an excel spreadsheet was transferred to the statistical software IBM SPSS $®$ software (Statistical Package for Social Sciences) version 24.0 for analysis. Before analyzing it, the database was weighed according to the governorate where pharmacy is located, based on the list provided by the OPL. Descriptive statistics were reported using frequency with percentages for categorical variables and mean and standard deviation for continuous variables. Given that the response to all of the questions was mandatory, no missing data was recorded. For descriptive analysis, frequency and percentage were used for categorical variables, the mean and standard deviation for quantitative variables. The normality distribution of $\mathrm{CBI}$ scale items was confirmed by calculation of skewness and kurtosis values which are lower than 1 [36]. The categorized CBI using a cut-off was used in the bivariate and multivariable analysis. For the bivariate analysis of continuous variables, the Chi- 2 test was used to compare categorical variables. All variables that showed a $p$-value $<0.2$ in the bivariate analysis were included in the multivariable analysis as independent variables. Four logistic regressions using were conducted to identify the correlates of each of the $\mathrm{CBI}$ scales using overall burnout, personal burnout, work-related burnout and client-related burnout respectively as dependent variable. A P-value less than 0.05 is considered statistically significant.

\section{Results}

\section{1-Baseline information of the participants:}

A total of 387 CPs participated in the survey. Of the total, $53.7 \%$ were females; $60.5 \%$ were married, $43.2 \%$ were aged less than 40 years old, and $65.9 \%$ were residents of urban areas. Around half of the participants hold a BS degree in pharmaceutical sciences, had less than 10 years of professional experience (56.9\%), working more than 40 hours per week (59.9\%), having a monthly income more than 2 Million Lebanese pounds (53.9\%) and were pharmacy' owner (55.3\%). Most of surveyed CPs worked in pharmacies located in Mount-Lebanon governorate, which is mainly operating around $50-120$ hours per week (81.6\%). Of note, $77.5 \%$ have a good health status. In terms of family members, nearly half of participants had currently a dependent child (55.5\%) or were living with the elderly (51.4\%) or a family member with comorbidities living with them at home (59.4\%). In terms of exposure, 
$76.7 \%$ of them were tested for COVID-19 and $23 \%$ were diagnosed with COVID-19. A detailed description of the baseline characteristics of the surveyed community pharmacists is presented in table 1.

\section{2-Description of the scales:}

In this sample of CPs, overall burnout had a mean of $65.34(S D=17.39)$ while the value for personal burnout, workrelated burnout and client-related burnout scales were $67.17(S D=16.82), 67.02(S D=14.15)$, and $69.38(S D=20.78)$ respectively. The normality of the all used scales was assumed since skewness and kurtosis were lower than 1 for all, and the sample size larger than 300. All the used scales showed good reliability; $\mathrm{CBI}(\mathrm{a}=0.868)$; personal burnout ( $\alpha=0.912)$; work-related burnout $(a=0.847)$, client-related burnout $(\alpha=0.891)$ and threat perception scale $(a=0.719)$. Quietly similar higher burnout level was shown in the dimension related to work $(67.02 \pm 14.15)$ and the one related to personal burnout $(67.17 \pm 17.39)$ followed by client-related burnout $(63.98 \pm 20.78)$. A detailed description of the scales is presented in Table 2.

\section{3- Risk perceptions and altruistic acceptance of risk during the COVID-19 pandemic}

More than $90 \%$ of surveyed CPs believed that their job was putting them at risk and were afraid to pass COVID-19 to others including their families and friends. In addition, $86.1 \%$ of them felt extra stress at work and $62.1 \%$ were afraid of falling ill with COVID-19, while $61.1 \%$ were worried that people avoid their families because of their work. More than half of CPs considered they had little control over being infected or not. $53.4 \%$ of participants were concerned that their families and friends feared to get infection through them. Only $1.03 \%$ of CPs believed that they would die if they get infected and $4.9 \%$ thought about resigning because of COVID-19. As for altruistic acceptance of risks, most participants (78.8\%) accepted taking the risk of caring for COVID-19 patients (Figure 1).

\section{Prevalence of burnout among Lebanese community pharmacists}

Using a cut-off of 50 for $\mathrm{CBI}$, burnout was detected among $81.9 \%$ of surveyed $\mathrm{CPs}$, where $61 \%$ had a moderate burnout and $20.9 \%$ had a high level of burnout. Client burnout (CB) ranked first among other burnout aspects, where we can found that $89.7 \%$ of CPs suffered from CB with $17.3 \%$ of them reported high levels. As for workrelated burnout (WB), it was detected moderate among more than three-quarters of CPs (76.8\%), where $37 \%$ of them presented a high level of WB. In regards to personal burnout (PB), it was detected among $77.8 \%$ of CPs. Notably, $65.9 \%$ of participants experienced high level of personal burnout (Figure 2). 
n $\quad \%$

\section{Gender}

Male

Female

\section{Age (years)}
Less than $40 \mathrm{y}$
$\geq 40$ y

\section{Marital status}

Single and other*

Married/Engaged

\section{Pharmacy location}

North \& Akkar

Mount Lebanon

Beirut

South \& Nabatyeh

Bekaa \& Baalbeck-Hermel

Urbanicity (Residency)

Rural

Urban

\section{Years of experience}

0-10 years

More than 10 years

\section{Profile}

Staff pharmacist

Owner

Manager

\section{Highest education level}

BS pharmacy

Other (Master, PharmD, PhD...)

Number of hours per week pharmacy is open

Less than 50 hours

\begin{tabular}{|l|l|}
\hline 179 & $46.30 \%$ \\
\hline 208 & $53.70 \%$ \\
\hline
\end{tabular}

$254 \quad 65.60 \%$

$133 \quad 34.40 \%$

$153 \quad 39.50 \%$

$234 \quad 60.50 \%$

$48 \quad 12.40 \%$

$145 \quad 37.50 \%$

$60 \quad 15.50 \%$

$79 \quad 20.40 \%$

$55 \quad 14.20 \%$

$132 \quad 34.10 \%$

$255 \quad 65.90 \%$

$220 \quad 56.90 \%$

$167 \quad 43.20 \%$

$135 \quad 34.90 \%$

$214 \quad 55.30 \%$

$38 \quad 9.80 \%$

$216 \quad 55.80 \%$

$171 \quad 44.20 \%$

$40 \quad 10.40 \%$ 
50-120 hours

7 days $24 / 24 h$

\section{Pharmacist working hours}

Less than $40 \mathrm{~h}$

40 hours or more

Household income

$<2$ Millions

$>2$ Millions

\section{Health status}

Fair and Below

Good and above

Presence of dependent child

No

Yes

Presence of elderly people at home

No

Yes

Living with family member with comorbidities

No

Yes

\section{Ever tested for COVID-19}

No

Yes

Personal history of COVID-19 diagnosis

No

Yes

Family member/friend ever diagnosed with COVID-19

No

Yes

Colleague ever diagnosed with COVID-19

No
316

31

$81.60 \%$

1

$8.00 \%$

\begin{tabular}{ll}
\hline 155 & $40.10 \%$ \\
\hline 232 & $59.90 \%$ \\
\hline 178 & $46.10 \%$ \\
\hline 209 & $53.9 \%$ \\
\hline
\end{tabular}

87

$22.50 \%$

300

$77.50 \%$

$172 \quad 44.50 \%$

$215 \quad 55.50 \%$

$188 \quad 48.60 \%$

$199 \quad 51.40 \%$

$157 \quad 40.60 \%$

$230 \quad 59.40 \%$

$90 \quad 23.30 \%$

$297 \quad 76.70 \%$

$298 \quad 77.00 \%$

$89 \quad 23.00 \%$

$256 \quad 66.10 \%$

$131 \quad 33.90 \%$ 
Note: $n$ : Frequency, \% Percentage, * Other included divorced or widowed 
Table 2: Descriptive statistics of the scales used in the study

\# Scale items

Mean S.D

TPS Threat perception scale $(a=0.719)$

$36.68 \quad 1.92$

Threat1 My job puts me at great risk

$3.96 \quad 0.63$

Threat2 I feel more stress at work

3.86

0.77

Threat3 I have little control over whether I get infected or not

$3.01 \quad 0.10$

Threat4 I have little chance of survival if I were to get SARS

$2.16 \quad 0.48$

Threat5 I think of resigning because of SARS

$2.16 \quad 0.48$

Threat6 I am afraid that I will pass SARS to others

$4.23 \quad 0.83$

Threat7 My family and friends are worried they get infected through me

$3.85 \quad 0.53$

Threat8 People avoid my family because of my work

$4.03 \quad 0.93$

Threat9 I am afraid of falling ill with SARS

$3.82 \quad 0.72$

ALtru1 I accept the risk of caring for SARS patient ${ }^{R}$

$3.63 \quad 0.74$

CBI Copenhagen burnout inventory scale $(a=0.868)$

$65.34 \quad 17.39$

Personal burnout $(a=0.912)$

$67.17 \quad 16.82$

PB1 How often do you feel tired?

$66.41 \quad 16.56$

PB2 How often you are physically exhausted?

$66.41 \quad 16.56$

PB3 How often you are emotionally exhausted?

$66.41 \quad 16.56$

PB4 How often do you think:"I can't take it anymore"?

$69.06 \quad 12.48$

PB5 How often do you feel worn out?

$67.38 \quad 16.88$

PB6 How often do you feel weak and susceptible to illness?

$67.38 \quad 16.88$

Work-related burnout $(a=0.847)$

$67.02 \quad 14.15$

WB1 Is your work emotionally exhausting?

$64.08 \quad 13.42$

WB2 Do you feel burnt out because of your work?

$68.67 \quad 11.18$

8WB3 Does your work frustrate you?

$69.12 \quad 11.91$

WB4 Do you feel worn out at the end of the working day?

$69.77 \quad 11.53$

WB5 Are you exhausted in the morning at the thought of another day at work?

$66.15 \quad 12.24$

WB6 Do you feel that every working hour is tiring for you?

$69.51 \quad 11.26$

WB7 Do you have enough energy for family and friends during leisure time? $\mathbf{R}$

66.6012 .09

Client burnout $(a=0.891)$

$69.38 \quad 20.78$

CB1

Do you find it hard to work with clients?

$68.27 \quad 21.39$

Page $11 / 30$ 


\begin{tabular}{llrc} 
CB3 & Does it drain your energy to work with clients? & 67.67 & 23.53 \\
\hline CB4 & Do you feel that you give more than you get back when you work with clients? & 68.82 & 24.29 \\
\hline CB5 & Are you tired of working with clients? & 72.03 & 24.98 \\
\hline CB6 & $\begin{array}{l}\text { Do you sometimes wonder how long you will be able to continue working with } \\
\text { clients? }\end{array}$ & 69.30 & 21.23
\end{tabular}

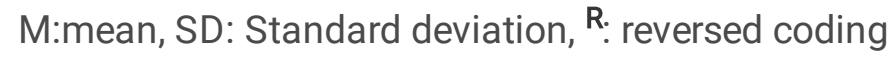

\section{Factors associated with overall burnout:}

Table 3 displayed factors associated with overall burnout among CPs. Female CPs (aOR=1.632, 95\% Cl (1.2133.381)) were 1.6 times more prone to higher level of burnout comparing to males. Similarly, younger CPs $(\mathrm{aOR}=1.792,95 \% \mathrm{Cl}(1.314-3.904))$, staff pharmacists (aOR=3.020, 95\% $\mathrm{Cl}(1.892-4.217)$ ) and CPs suffering from comorbidities $(\mathrm{aOR}=2.312,95 \% \mathrm{Cl}(1.541-3.871)$ ) were more likely to experience higher level of burnout than older CPs and pharmacy' owner. In the contrary, married CPs (aOR=0.731, 95\% $\mathrm{Cl}(0.598-0.834)$ ) were less likely to suffer from higher burnout comparing to CPs without partner. Having large professional experience (aOR=0.621, $95 \% \mathrm{Cl}(0.502-0.833)$ ), sufficient sleeping hours (aOR=0.609, 95\% $\mathrm{Cl}(0.323-0.898)$ ) and higher socio-economic status $(\mathrm{aOR}=0.452,95 \% \mathrm{Cl}(0.238-0.611))$ were associated with lower burnout level. However, working in pharmacies operating round the clock $(\mathrm{aOR}=3.78,95 \% \mathrm{Cl}(2.113-5.487))$ and extensive working hours (aOR=2.311, 95\% $\mathrm{Cl}(1.817-3.087)$ ) were associated with higher odds of burnout. In terms of living conditions, having a dependent child $(\mathrm{aOR}=4.171,95 \% \mathrm{Cl}(3.273-8.312)$ ), living with family member with comorbidities (aOR=3.028, 95\% Cl (2.139-5.123)) and having high perception of COVID-19 threat (aOR=1.303, 95\% Cl (1.187-2.786)) were associated positively with higher level of burnout. However, having a previous history of COVID-19 (aOR=0.765, $95 \% \mathrm{Cl}(0.436-0.908)$ ) and accepting the risk of dealing with COVID-19 (aOR=0.652, 95\% Cl (0.583-0.789)) were associated with lower odds of burnout. 
Table 3: Factors associated with the overall burnout scale

\begin{tabular}{llllll} 
Low $(<50)$ & High $(\geq 50)$ & & & \multicolumn{2}{c}{$\begin{array}{l}\text { Confidence } \\
\text { Interval } 95 \%\end{array}$} \\
\hline $\mathrm{n}(\%)$ & $\mathrm{n}(\%)$ & Total & $\begin{array}{l}\text { P- } \\
\text { value }\end{array}$ & aOR & Lower Upper
\end{tabular}

\begin{tabular}{|c|c|c|c|c|c|c|c|}
\hline Gender & & & & 0.003 & & & \\
\hline Male & $49(27.4 \%)$ & $130(72.6 \%)$ & $179(46.3 \%)$ & & Ref & & \\
\hline Female & $21(10.1 \%)$ & 187(89.9\%) & $208(53.7 \%)$ & & 1.632 & 1.213 & 3.381 \\
\hline Age (years) & & & & 0.023 & & & \\
\hline$\geq 40 y$ & $31(23.3 \%)$ & $102(76.7 \%)$ & $133(34.4 \%)$ & & Ref & & \\
\hline Less than $40 \mathrm{y}$ & $39(15.4 \%)$ & $293(84.6 \%)$ & $254(65.6 \%)$ & & 1.792 & 1.342 & 3.904 \\
\hline Marital status & & & & 0.041 & & & \\
\hline Single and other* & $18(11.8 \%)$ & 135(88.2\%) & $153(39.5 \%)$ & & Ref & & \\
\hline Married/Engaged & $42(17.9 \%)$ & 192(82.1\%) & $234(60.5 \%)$ & & 0.731 & 0.598 & 0.834 \\
\hline $\begin{array}{l}\text { Pharmacy } \\
\text { location }\end{array}$ & & & & 0.187 & & & \\
\hline North \& Akkar & $9(18.7 \%)$ & $39(81.3 \%)$ & $48(12.4 \%)$ & & & & \\
\hline Mount Lebanon & $31(21.4 \%)$ & $124(79.6 \%)$ & $145(37.5 \%)$ & & & & \\
\hline Beirut & $10(16.7 \%)$ & $50(83.3 \%)$ & $60(15.5 \%)$ & & & & \\
\hline $\begin{array}{l}\text { South \& } \\
\text { Nabatyeh }\end{array}$ & $15(18.9 \%)$ & $64(81.2 \%)$ & $79(20.4 \%)$ & & & & \\
\hline $\begin{array}{l}\text { Bekaa \& } \\
\text { Baalbeck-Hermel }\end{array}$ & $7(12.72 \%)$ & $48(87.2 \%)$ & $55(14.2 \%)$ & & & & \\
\hline $\begin{array}{l}\text { Years of } \\
\text { experience }\end{array}$ & & & & 0.028 & & & \\
\hline $0-10$ years & $22(10 \%)$ & 198(90\%) & $220(56.9 \%)$ & & Ref & & \\
\hline $\begin{array}{l}\text { More than } 10 \\
\text { years }\end{array}$ & $48(28.7 \%)$ & 119(71.3\%) & 167(43.2\%) & & 0.621 & 0.502 & 0.833 \\
\hline Profile & & & & 0.021 & & & \\
\hline Owner & $49(22.8 \%)$ & 165(77.1\%) & $214(55.3 \%)$ & & Ref & & \\
\hline Manager & $9(23.7 \%)$ & $29(76.3 \%)$ & $38(9.8 \%)$ & & 1.261 & 0.913 & 1.512 \\
\hline Staff pharmacist & $12(8.9 \%)$ & 123(91.1\%) & 135(34.9\%) & & 3.02 & 1.892 & 4.217 \\
\hline $\begin{array}{l}\text { Highest } \\
\text { education level }\end{array}$ & & & & 0.119 & & & \\
\hline BS pharmacy & $41(18.9 \%)$ & $175(81.1 \%)$ & $216(55.8 \%)$ & & & & \\
\hline
\end{tabular}




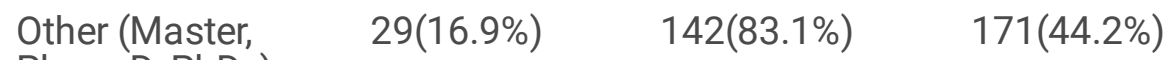

PharmD, PhD..)

Number of hours per week pharmacy is open

$<0.001$

Less than 50 hours

$21(27.5 \%) \quad 29(72.5 \%) \quad 40(10.4 \%)$

Ref

50-120 hours

$46(14.5 \%) \quad 260(85.5 \%) \quad 316(81.6 \%)$

$1.92 \quad 0.989 \quad 2.338$

7 days $24 / 24 h$

$3(9.7 \% \quad 28(90.3 \%) \quad 31(8 \%)$

3.78

$2.113 \quad 5.487$

Pharmacist working hours

$<0.001$

Less than $40 \mathrm{~h}$

48(31\%) 107(69\%)

$155(40.1 \%)$

Ref

40 hours or more

$22(9.5 \%) \quad 210(90.5 \%)$

$232(59.9 \%)$

$2.311 \quad 1.817 \quad 3.087$

Subjective classification of the current economic situation

$<0.001$

Low

17(6.1\%) 261(95.7\%)

278(46.4\%)

Ref

Middle

$38(28.8 \%) \quad 42(71.2 \%)$

$80(20.7 \%)$

$\begin{array}{lll}0.865 & 0.467 & 1.897\end{array}$

High

15(51.7\%) 14(48.3\%)

$29(43.6 \%)$

0.452

$0.238 \quad 0.611$

Having am underlying condition/comorbidity

0.023

\begin{tabular}{lllllll} 
No & $61(20.5 \%)$ & $237(79.5 \%)$ & $298(77.00 \%)$ & & Ref & \\
\hline Yes & $9(10.1 \%)$ & $80(89.9 \%)$ & $89(23 \%)$ & & 2.312 & 1.541 \\
\hline $\begin{array}{l}\text { Presence of } \\
\text { dependent child }\end{array}$ & & & & $<.871$ \\
\hline
\end{tabular}

\begin{tabular}{lllllll} 
No & $58(33.7 \%)$ & $114(66.27 \%)$ & $172(44.5 \%)$ & \multicolumn{2}{l}{ Ref } & \\
\hline Yes & $12(5.6 \%)$ & $203(89.9 \%)$ & $215(55.5 \%)$ & 4.171 & 3.273 & 8.312
\end{tabular}

Living with family member with comorbidities

$<0.001$

\begin{tabular}{lllllll} 
No & $52(33.1 \%)$ & $105(66.7 \%)$ & $157(40.6 \%)$ & \multicolumn{2}{l}{ Ref } & \\
Yes & $18(7.8 \%$ & $212((92.2 \%)$ & $230(59.4 \%)$ & 3.028 & 2.139 & 5.123
\end{tabular}

Personal history of

COVID-19 diagnosis

$<0.001$

\begin{tabular}{lllllll} 
No & $53(89.9 \%)$ & $245(89.9 \%)$ & $298(77 \%)$ & \multicolumn{2}{l}{ Ref } & \\
\hline Yes & $27(89.9 \%)$ & $62(89.9 \%)$ & $89(23 \%)$ & 0.765 & 0.436 & 0.908
\end{tabular}

Family

member/friend ever

0.189

diagnosed with

COVID-19

$\begin{array}{llll}\text { No } & 46(17.9 \%) & 210(82.1 \%) & 256(66.1 \%) \\ \text { Yes } & 24(18.3 \%) & 107(81.7 \%) & 131(33.9 \%)\end{array}$




\begin{tabular}{lllllllll}
\hline No & $7(20 \%)$ & $28(80 \%)$ & $35(9 \%)$ & & & & \\
\hline Yes & $63(17.9 \%)$ & $289(82.1 \%)$ & $352(91 \%)$ & & & & \\
\hline Sleeping hours & & & & 0.008 & & & \\
\hline$<6$ hours & $23(13.8 \%)$ & $154(86.2 \%)$ & $167(43.2 \%)$ & & Ref & & \\
\hline$\geq 6$ hours & $47(21.4 \%)$ & $173(78.6 \%)$ & $220(56.8 \%)$ & & 0.609 & 0.323 & 0.898 \\
\hline Altruism & & & & 0.002 & & & \\
\hline Disagree & $8(9.7 \%)$ & $76(91.3 \%)$ & $82(21.25 \%)$ & & Ref & & \\
\hline Agree & $62(20.3 \%)$ & $243(79.7 \%)$ & $305(78.8 \%)$ & & 0.652 & 0.583 & 0.789 \\
\hline $\begin{array}{l}\text { Threat perception } \\
\text { scale }\end{array}$ & & & & 0.044 & 1.303 & 1.187 & 2.786 \\
\hline
\end{tabular}

Note: n: Frequency, \% Percentage, *Other included divorced or widowed, C.I: Confidence interval, aOR: adjusted Odds Ratio

\section{Factors associated with personal burnout:}

Younger age $(\mathrm{aOR}=1.792,95 \% \mathrm{Cl}(1.342-1.904))$, female gender $(\mathrm{aOR}=2.632,95 \% \mathrm{Cl}(1.913-4.187))$, being staff pharmacist (aOR=2.116, 95\% Cl (1.618-3.807)), working more than 40 hours per week (aOR=1.663, 95\% $\mathrm{Cl}(1.321$ 2.732)) were positively associated with higher level of burnout. Similarly, having a dependent child $(\mathrm{aOR}=2.632$, $95 \% \mathrm{Cl}(1.913-4.187))$, insufficient sleeping hours (aOR=3.219, 95\% $\mathrm{Cl}(2.013-6.127))$, having a colleague diagnosed with COVID-19 (aOR=1.852, 95\% Cl (1.347-2.786)) and high perception of COVID-19 threat (aOR=1.852, $95 \% \mathrm{Cl}(1.347-2.786))$ were also associated with higher burnout. However, $\mathrm{CPs}$ who were married (aOR=0.876, $95 \% \mathrm{Cl}(0.669-0.942))$, having high socioeconomic situation (aOR=0.367, $95 \% \mathrm{Cl}(0.218-0.605)$ ), and accepting the risk of dealing with COVID-19 cases ( $a O R=0.812,95 \% \mathrm{Cl}(0.623-0.918)$ ) were less likely to experience high level of burnout comparing to their counterparts (Table 4). 
Table 4: Factors associated with Personal burnout scale among CPS

\begin{tabular}{lllllll}
$\begin{array}{l}\text { Low } \\
(<50)\end{array}$ & High $(\geq 50)$ & & & \multicolumn{3}{c}{$\begin{array}{l}\text { Confidence } \\
\text { interval } 95 \%\end{array}$} \\
\hline$n(\%)$ & $n(\%)$ & Total & $\begin{array}{l}\text { P- } \\
\text { value }\end{array}$ & aOR & Lower & Upper \\
\hline
\end{tabular}

\begin{tabular}{|c|c|c|c|c|c|c|c|}
\hline Gender & & & & 0.022 & & & \\
\hline Male & $48(26.8 \%)$ & $138(73.2 \%)$ & $179(46.3 \%)$ & & Ref & & \\
\hline Female & $38(18.3 \%)$ & $170(81.7 \%)$ & $208(53.7 \%)$ & & 2.632 & 1.913 & 4.187 \\
\hline Age (years) & & & & 0.023 & & & \\
\hline$\geq 40 y$ & $50(37.5 \%)$ & $83(62.5 \%)$ & $133(34.4 \%)$ & & Ref & & \\
\hline Less than $40 \mathrm{y}$ & $36(14.2 \%)$ & $218(85.8 \%)$ & $254(65.6 \%)$ & & 1.792 & 1.342 & 1.904 \\
\hline Marital status & & & & 0.048 & & & \\
\hline Single and other* & $39(25.4 \%)$ & $114(74.6 \%)$ & 153(39.5\%) & & Ref & & \\
\hline Married/Engaged & $47(20 \%)$ & $187(80 \%)$ & $234(60.5 \%)$ & & 0.876 & 0.669 & 0.942 \\
\hline Profile & & & & 0.039 & & & \\
\hline Owner & $54(25.2 \%)$ & $160(74.8 \%)$ & $214(55.3 \%)$ & & Ref & & \\
\hline Manager & $8(21.1 \%)$ & $30(79.9 \%)$ & $38(9.8 \%)$ & & 1.213 & 0.907 & 1.813 \\
\hline Staff pharmacist & $24(17.7 \%)$ & $111(82.3 \%)$ & $135(34.9 \%)$ & & 2.116 & 1.618 & 3.807 \\
\hline $\begin{array}{l}\text { Pharmacist working } \\
\text { hours }\end{array}$ & & & & 0.026 & & & \\
\hline Less than $40 \mathrm{~h}$ & $32(20.6 \%)$ & $123(79.4 \%)$ & $155(40.1 \%)$ & & Ref & & \\
\hline 40 hours or more & $54(23.2 \%)$ & $178(76.8 \%)$ & $232(59.9 \%)$ & & 1.663 & 1.321 & 2.732 \\
\hline $\begin{array}{l}\text { Subjective classification } \\
\text { of the current economic } \\
\text { status }\end{array}$ & & & & $<0.001$ & & & \\
\hline Low & $49(16.9 \%)$ & $242(87.1 \%)$ & $278(46.4 \%)$ & & Ref & & \\
\hline Middle & $16(21.3 \%$ & $63(78.7 \%)$ & $80(20.7 \%)$ & & 0.871 & 0.689 & 0.914 \\
\hline High & $21(72 \%)$ & 187(89.9\%) & $29(43.6 \%)$ & & 0.367 & 0.218 & 0.605 \\
\hline $\begin{array}{l}\text { Presence of dependent } \\
\text { child }\end{array}$ & & & & $<0.001$ & & & \\
\hline No & $66(38.9 \%)$ & $106(61.1 \%)$ & $172(44.5 \%)$ & & Ref & & \\
\hline Yes & $20(9.3 \%)$ & $195(90.7 \%)$ & $215(55.5 \%)$ & & 4.017 & 3.818 & 7.432 \\
\hline
\end{tabular}

Personal history of COVID-19 diagnosis

0.079

\begin{tabular}{llll} 
No & $70(23.4 \%)$ & $228(76.6 \%)$ & $298(77 \%)$ \\
Yes & $16(17.9 \%)$ & $73(82.1 \%)$ & $89(23 \%)$ \\
& \multicolumn{3}{c}{ Page $16 / 30$} \\
\hline
\end{tabular}


Family member/friend ever diagnosed with COVID-19

0.102

\begin{tabular}{lccllllll}
\hline No & $55(21.5 \%)$ & $201(79.5 \%)$ & $256(66.1 \%)$ & & & & \\
\hline Yes & $31(23.7 \%)$ & $100(76.3 \%)$ & $131(33.9 \%)$ & & & & \\
\hline \multicolumn{1}{l}{ Colleague ever diagnosed with COVID-19 } & & & 0.006 & & & \\
\hline No & $19(54.3 \%)$ & $16(45.7 \%)$ & $35(9 \%)$ & & Ref & & \\
\hline Yes & $67(19.1 \%)$ & $285(80.9 \%)$ & $352(91 \%)$ & & 4.73 & 2.782 & 7.112 \\
\hline Sleeping hours & & & & $<0.001$ & & & \\
\hline$\geq 6$ hours & $54(24.5 \%)$ & $166(75.5 \%)$ & $220(56.8 \%)$ & & Ref & & \\
\hline$<6$ hours & $32(19.1 \%)$ & $135(86.2 \%)$ & $167(43.2 \%)$ & & 3.219 & 2.013 & 6.127 \\
\hline Altruism & & & & 0.042 & & & \\
\hline Disagree & $20(24.4 \%)$ & $62(75.6 \%)$ & $82(21.25 \%)$ & & Ref & & \\
\hline Agree & $66(21.6 \%)$ & $239(78.4 \%)$ & $305(78.8 \%)$ & & 0.812 & 0.623 & 0.918 \\
\hline $\begin{array}{l}\text { Threat perception } \\
\text { scale }\end{array}$ & & & & 0.032 & 1.852 & 1.347 & 2.786 \\
\hline
\end{tabular}

Note: $n$ : Frequency, \% Percentage, *Other included divorced or widowed. C.I: Confidence interval, aOR: adjusted Odds Ratio 
Table 5: Factors associated with work-related burnout scale among CPs

\begin{tabular}{lllllll} 
Low $(<50)$ & High $(\geq 50)$ & & & \multicolumn{3}{c}{$\begin{array}{c}\text { Confidence } \\
\text { interval } 95 \%\end{array}$} \\
\hline$n(\%)$ & $n(\%)$ & Total & $\begin{array}{l}\text { P- } \\
\text { value }\end{array}$ & aOR & Lower & Upper
\end{tabular}

Age (years)

$\geq 40 \mathrm{y}$

Less than $40 \mathrm{y}$

Years of experience

$0-10$ years

More than 10 years

Profile

Owner

Manager

Staff pharmacist

Number of hours per week pharmacy is open

Less than 50 hours

$20(50 \%)$

50-120 hours

7 days $24 / 24 \mathrm{~h}$

Pharmacist working hours

65(20.5\%)

$5(16.1 \%)$

Less than $40 \mathrm{~h}$

40 hours or more

$$
58(37.4 \%)
$$

$32(13.7 \%)$

Presence of underlying condition

No

$73(24.4 \%)$

$17(19.1 \%)$

Presence of dependent child

$$
\text { No }
$$

Yes

$$
70(40.7 \%)
$$$$
20(9.3 \%)
$$

Dealing with COVID-19 case

$$
\text { No }
$$

Yes

Sleeping hours
$60(29.7 \%)$

$30(16.3 \%)$

\begin{tabular}{ll}
\hline $91(68.4 \%)$ & $133(34.4 \%)$ \\
\hline $206(91.1 \%)$ & $254(65.6 \%)$
\end{tabular}

0.023

\subsection{3}

Ref

$2.132 \quad 1.168 \quad 3.005$

0.013

181(82.3\%) 220(56.9\%)

116(69.5\%) 167(43.2\%)

0.761

0.532

0.898

0.011

149(69.7\%) 214(55.3\%)

Ref

$24(63.2 \%) \quad 38(9.8 \%)$

$\begin{array}{lll}1.812 & 0.923 & 3.107\end{array}$

$\begin{array}{lll}4.12 & 2.192 & 6.117\end{array}$

124(91.8\%) 135(34.9\%)

$<0.001$

Ref

$\begin{array}{lll}3.128 & 2.129 & 5.338\end{array}$

$\begin{array}{lll}4.178 & 2.781 & 6.553\end{array}$

$<0.001$

Ref

$\begin{array}{lll}1.709 & 1.221 & 3.405\end{array}$

$<0.001$

Ref

$\begin{array}{lll}1.821 & 1.239 & 3.011\end{array}$

$<0.001$

Ref

$2.361 \quad 1.765 \quad 3.812$

0.032

\begin{tabular}{lll}
\hline $102(59.3 \%)$ & $172(44.5 \%)$ & \\
\hline $195(90.7 \%)$ & $215(55.5 \%)$ & \\
\hline & & $\mathbf{0 . 0 3 2}$
\end{tabular}

Ref

$\begin{array}{lll}1.912 & 1.682 \quad 3.829\end{array}$

\begin{tabular}{ll}
$142(70.3 \%)$ & $202(48.1 \%)$ \\
\hline $155(83.7 \%)$ & $185(51.9 \%)$
\end{tabular}




\begin{tabular}{|c|c|c|c|c|c|c|c|}
\hline$\geq 6$ hours & $64(29.1 \%)$ & $156(70.9 \%)$ & $220(56.8 \%)$ & & Ref & & \\
\hline$<6$ hours & $26(15.5 \%)$ & $141(84.4 \%)$ & $167(43.2 \%)$ & & 2.918 & 1.812 & 5.218 \\
\hline \multicolumn{4}{|c|}{ Subjective classification of the current economic status } & \multicolumn{4}{|l|}{$<0.001$} \\
\hline Low & $50(17.9 \%)$ & $228(82.1 \%)$ & $278(46.4 \%)$ & & Ref & & \\
\hline Middle & $22(27.5 \%)$ & $58(72.5 \%)$ & $80(20.7 \%)$ & & 0.871 & 0.689 & 1.914 \\
\hline High & $18(62.1 \%)$ & $11(37.9 \%)$ & $29(43.6 \%)$ & & 0.367 & 0.218 & 0.605 \\
\hline \multicolumn{4}{|l|}{ Altruism } & \multicolumn{4}{|l|}{0.042} \\
\hline Disagree & $66(80.4 \%)$ & $16(19.6 \%)$ & $82(21.25 \%)$ & & Ref & & \\
\hline Agree & $24(7.9 \%)$ & $281(92.1 \%)$ & $305(78.8 \%)$ & & 0.722 & 0.512 & 0.909 \\
\hline \multicolumn{4}{|l|}{$\begin{array}{l}\text { Threat perception } \\
\text { scale }\end{array}$} & 0.016 & 2.853 & 1.472 & 3.885 \\
\hline \multicolumn{4}{|c|}{ Colleague ever diagnosed with COVID-19 } & 0.001 & & & \\
\hline No & $20(57.1 \%)$ & $15(42.9 \%)$ & $35(9 \%)$ & & Ref & & \\
\hline Yes & $70(19.9 \%)$ & $282(80.1 \%)$ & $352(91 \%)$ & & 3.819 & 2.011 & 7.415 \\
\hline
\end{tabular}


Table 6: Factors associated with the client-related burnout scale

\begin{tabular}{|c|c|c|c|c|c|c|c|}
\hline & \multirow{2}{*}{$\begin{array}{l}\text { Low }(<50) \\
n(\%)\end{array}$} & \multicolumn{4}{|l|}{$\operatorname{High}(\geq 50)$} & \multicolumn{2}{|c|}{ Confidence interva } \\
\hline & & $n(\%)$ & Total & P-value & aOR & Lower & Upper \\
\hline \multicolumn{4}{|l|}{ Age (years) } & 0.023 & & & \\
\hline$\geq 40 y$ & $31(23.3 \%)$ & $102(76.7 \%)$ & $133(34.4 \%)$ & & Ref & & \\
\hline Less than $40 \mathrm{y}$ & $39(15.4 \%)$ & $293(84.6 \%)$ & $254(65.6 \%)$ & & 1.792 & 1.342 & 1.904 \\
\hline \multicolumn{4}{|l|}{ Profile } & 0.021 & & & \\
\hline Owner & $53(24.7 \%)$ & $161(75.3 \%)$ & $214(55.3 \%)$ & Ref & & & \\
\hline Manager & $7(18.4 \%)$ & $31(81.6 \%)$ & $38(9.8 \%)$ & & 1.322 & 0.879 & 3.512 \\
\hline Staff pharmacist & $10(7.4 \%)$ & $123(92.6 \%)$ & $135(34.9 \%)$ & & 3.021 & 1.892 & 5.327 \\
\hline \multicolumn{4}{|c|}{ Pharmacist working hours } & $<0.001$ & & & \\
\hline Less than $40 \mathrm{~h}$ & $49(31.6 \%)$ & $106(68.4 \%)$ & $155(40.1 \%)$ & & Ref & & \\
\hline 40 hours or more & $21(9.1 \%)$ & $211(89.9 \%)$ & $232(59.9 \%)$ & & 4.302 & 2.918 & 7.503 \\
\hline \multicolumn{4}{|c|}{ Dealing with COVID-19 case } & 0.012 & & & \\
\hline No & $65(32.2 \%)$ & $137(67.8 \%)$ & $202(48.1 \%)$ & & Ref & & \\
\hline Yes & $5(2.7 \%)$ & $180(97.3 \%)$ & $185(51.9 \%)$ & & 3.781 & 1.467 & 7.412 \\
\hline \multicolumn{8}{|l|}{ Altruism } \\
\hline Disagree & $8(9.5 \%)$ & $58(91.5 \%)$ & $82(21.25 \%)$ & & Ref & & \\
\hline Agree & $62(20.3 \%)$ & $243(79.7 \%)$ & $305(78.8 \%)$ & & 0.582 & 0.381 & 0.765 \\
\hline \multicolumn{4}{|l|}{ Threat perception } & 0.043 & 2.032 & 1.283 & 4.066 \\
\hline
\end{tabular}

\section{Factors associated with work-related burnout}

Younger age $\mathrm{CPs}(\mathrm{aOR}=2.132,95 \% \mathrm{Cl}(1.168-3.005))$, CPs working as staff pharmacist (aOR=4.12, 95\% $\mathrm{Cl}(2.192-$ 6.117)), with extensive working hours ( $\mathrm{aOR}=1.709,95 \% \mathrm{Cl}(1.221-3.405)$ ), having a dependent child $(\mathrm{aOR}=2.361$, $95 \% \mathrm{Cl}(1.765-3.812))$ and dealing with COVID-19 cases (aOR=1.912, 95\% $\mathrm{Cl}(1.682-3.829)$ ) were more prone to have higher level of burnout. Similarly, working in a pharmacy which is operating more than 50 hours per week ( $\mathrm{aOR}=4.178,95 \% \mathrm{Cl}(2.781-6.553))$, having insufficient sleeping hours (aOR=2.918, 95\% $\mathrm{Cl}(1.812-5.218)$ ), having a colleague diagnosed with COVID-19 (aOR=3.819, 95\% Cl (2.011-7.415)) and high perception of COVID-19 threat $(\mathrm{aOR}=2.853,95 \% \mathrm{Cl}(1.473-3.885)$ ), were also associated with higher burnout. However, CPs who have high socioeconomic status ( $\mathrm{aOR}=0.367,95 \% \mathrm{Cl}(0.218-0.605))$, those who accepted the risk of dealing with COVID-19 cases (aOR $=0.722,95 \% \mathrm{Cl}(0.512-0.909))$ and those with large professional experience $(\mathrm{aOR}=0.761,95 \% \mathrm{Cl}$ (0.532-0.898)) were less likely to have high level of burnout comparing to their counterparts (Table 5). 


\section{Factors associated with client-related burnout}

As seen in table 6, the odds of client-related burnout was higher among younger $\mathrm{CPs}(\mathrm{aOR}=1.792,95 \% \mathrm{Cl}(1.342-$ 1.904)), staff pharmacists (aOR=3.021, 95\% Cl (1.892-5.327)), those who worked for more than 40 hours $(\mathrm{aOR}=4.302,95 \% \mathrm{Cl}(2.918-7.503))$, those dealing with COVID-19 cases (aOR=3.781, 95\% Cl (1.461-7.412)) and those who had higher perception of COVID-19 threat (aOR=2.032, 95\% Cl (1.283-4.066)). However, altruism $(\mathrm{aOR}=0.582,95 \% \mathrm{Cl}(0.381-0.765))$ was negatively associated to higher level of burnout.

\section{Discussion}

To the best of our knowledge, this study is the first nationwide survey assessing burnout syndrome among CPs during the COVID-19 pandemic and examining factors associated with burnout. Our results showed that burnout was prevalent among $81.9 \%$ of surveyed CPs and client-related burnout was the most expressed aspect of burnout (89.7\%). Younger age, female gender, being staff pharmacist, working in pharmacy operating around the clock and working more than 40 hours per week were associated with higher level of burnout. Similarly, suffering from comorbidity, having a dependent child or living a family member with comorbidities, experiencing sleep disturbance and high perception of COVID-19 threat were also associated with higher burnout. However, being married, having large professional experience, having high socioeconomic situation, accepting the risk of dealing with COVID-19 cases and having previous history of COVID-19 were negatively associated with burnout. On the other hand no relation was found between burnout and geographical location of the pharmacy as well as the education level.

Our findings showed that more than $80 \%$ of Lebanese CPs suffered from burnout and $20.9 \%$ of them had high level of burnout. This was predictable since Lebanese CPs were stranded under a perfect storm that could instigate burnout. Our results were higher than what has been reported in other studies. A study conducted among CPs showed that $74.9 \%$ of respondents experienced burnout in at least 1 of the 3 subscales of the MBI-HSS [37]. A study conducted in Serbia reported that $44.4 \%$ of community pharmacists had high levels of burnout [38]. A systematic review found the prevalence of burnout in pharmacists ranged from $19 \%$ to $37 \%$ [21]. Another study conducted among pharmacists in Saudi Arabia showed that $25.16 \%$ of pharmacists had high emotional exhaustion, 55.97\% had high depersonalization, and 63.52\% had low scores for personal accomplishment [39]. However, such comparison should be cautious since different scales were used.

In terms of work-related burnout, our results showed that $76.8 \%$ of surveyed CPs suffered from WB and $37 \%$ of them reported high level of WB. Overall, such alarming level of burnout among CPs in all three dimensions stressed the importance of urgent action to tackle such epidemic. Due to the uncertainty of the length of the current pandemic and the ongoing economic crisis, no one can neglect the considerable lasting impact of this syndrome.

In terms of sociodemographic factors associated with burnout, the first relevant finding was associated to the role of gender on the development of burnout among CPs. Our results showed that female CPs were more likely to experience high level of burnout comparing to males. Our results were consistent with the findings of a nationwide survey performed among the American Pharmaceutical Association membership which revealed higher level of burnout in women with respect to men pharmacists [40]. A study conducted among CPs in central Italy demonstrated no significant differences in burnout levels [41]. In the contrast, other studies disclosed that men suffer significantly more of burnout than women and men seem to suffer more from higher levels of stress [42- 
44]. In addition, younger age was found to be associated with higher level of burnout. Consistently to a study conducted in United States by Jones et al. among hospital clinical pharmacy practitioners where age was found to be protective against burnout [12]. Our findings showed that younger CPs were more prone to burnout comparing to older CPs. This could explained by the fact that younger pharmacists have the most workload, as the beginning of a pharmacist's job can be loaded with night shifts, and maintaining patient's safety, which can enhance the feeling of disconnect with themselves However, a study conducted in Serbia found that burnout was more common among older community pharmacists (51-60 years) compared with their younger colleagues [38]. These results can be clarified seeing that younger pharmacists have less professional experience, and thus, they presumably present a greater emotional load during their compared to older ones.

Comparing to pharmacy owners, staff pharmacists had higher odds of burnout. These results were in line with the findings of an Italian study which revealed that CPs most exposed to exhaustion were those who played the role of employee compared to those who held the role of holder, manager or other management roles [41]. Such finding was expected, as the staff pharmacists experience a relevant workload and were more exposed to clients than managers and owners, especially in larger pharmacies [45]. In terms of health status, CPs suffering from comorbidities were more likely to experience higher level of burnout than those with good health status. These findings were not surprising since subjects with COVID-19 were more concerned about their health which can prompt a high level of anxiety which can lead in turn to high level of burnout. This was supported by a study conducted among CPs pharmacists and pharmacy technicians that reported strong association between burnout syndrome and the presence of comorbidities such as depression and anxiety [42].

With regard to marital status, married CPs were found less likely to suffer from higher burnout comparing to unmarried CPs including single, widowed and divorced. Consistently with other studies, unmarried respondents had significantly higher exhaustion than married [46]. This could be explained by the fact that CPs who were receiving support from their partners experience less burnout when compared to those who do not. Of note, one of the suggested ideas found in the literature to overcome burnout was the building of support systems through family to enhance self-esteem and reduce burnout.

Interestingly, CPs with large professional experience had lower level of burnout comparing with those with a work experience less than 10 years. Several studies highlighted the role of years of practice in lowering level of burnout. For example, a study conducted in Turkey, found that burnout was higher in pharmacists working for less than 10 years than those working for 10-19 years and more than 29 years [44]. Calgan et al. reported that pharmacists who worked for less than 10 years have a higher level of emotional exhaustion and depersonalization than those working for more than 10 years. Similarly, Durham et al. reported that pharmacists working for less time were more exposed to burnout [11]. In these studies, experience seems to be a protective factor for burnout risk. This could be explained by the fact, that the CPs adapt themselves to confront job stressors and learn to cope with challenging situations. However, older experienced pharmacists have spent several/many years of their life in contact with patients, and probably, they have "accumulated" greater fatigue and exhaustion. Therefore, there were incongruent findings related years of practice experience [40, 47-49].

In regards to sleeping hours, our study showed that sleeping more than 6 hours daily was associated with lower level of burnout. Of note, the role of extensive working hours and sleep deprivation, were reported as risk factor for 
burnout among CPs in several studies especially when working in pharmacies operating round the clock with night shift $[20,49]$.

With the economic collapse and the steep loss of the value of the Lebanese currency combined with the inflation of the prices of the medicines and the imposed lockdown, concerns of Lebanese population towards an imminent shortage in medicines in the Lebanese market turned them into panic mode, and an unprecedented race to purchase medicines from pharmacies was reported. Hence, Lebanese CPs are facing intense workload, extensive working hours, which eventually impact physicians sleeping hours and burnout $[50,51]$.

A study conducted prior to the pandemic showed that $33 \%$ of the HCWs were screened positive for the sleeping disorder and this was associated with 4-fold bigger odds of burnout [52]. These results were in line with the findings among Saudi Arabian pharmacists where Sleeping hours per day were significantly correlated with burnout. Of note, sleep disturbances was positively associated with impaired performance, emotional changes, tiredness, loss of concentration, and mood disorders as anxiety or depression [53]. In addition to all of the above high socio-economic status $(\mathrm{aOR}=0.452,95 \% \mathrm{Cl}(0.238-0.611)$ ) were associated with lower burnout level. Several studies showed a correlation income satisfaction and burnout. Other study showed that low annual salary was associated with higher burnout [46]. In terms of living conditions, having a dependent child, living with family member with comorbidities was associated with higher burnout level. This could be due to the fears expressed by CPs to transfer the infection to their families especially for family members with comorbidities as they were more at risk of COVID-19 complications. Similarly higher perception of COVID-19 threat, in terms of catching the infection, transmission of the COVID-19, stigmatization of family was associated with higher level of burnout. These findings were not surprising as CPs believed that their job was putting them at risk and were afraid to pass COVID-19 to others including their families and friends. However, a study showed that pharmacists who had no children were more susceptible to exhaustion [46]. Remarkably, CPs with previous history of COVID-19 expressed lower level of burnout. Such finding could be due that CPs felt less anxious about COVID-19. Their natural immunity offers them a feeling of control over the infection. Lastly, accepting the risk of dealing with COVID-19 was associated with lower odds of burnout among CPs. As for altruistic acceptance of risks, most participants (78.8\%) accepted taking the risk of caring for COVID-19 patients

Several limitations should be acknowledged in our study. First, the cross-sectional design of our study does not allow us to infer causality or temporal order. In addition, the sample was not random; hence, selection bias is possible due to the used snowball technique for data collection which limits the generalizability of the findings. Unfortunately, given the online nature of collection tool, we are unable to report a response rate of those who our study was actually applicable to complete, as the query generated by ACCP was only able to tell us the total number of individuals who participate. However, our data was weighed by geographical location according to the list of CPs provided by the OPL, in addition our study involve a great variability of demographic characteristics, lifestyles, and working conditions, therefore, our results may represent the best representative case scenario of pharmacists' burnout. The collected data was also based on self-reported information which makes it disposed to social desirability and might drive the results towards the null, leading to underestimation of some associations. Furthermore, because survey respondents voluntarily completed the survey, only those who may have had available time during the pandemic may have participated. This may have led us to capture less of a selection of CPs that had higher demands on the job during this period, possibly leading to underreporting of burnout during the pandemic. On other hand, another possibility was that CPs who were suffering from this syndrome were more interested to participate. In addition, lack of reward for completing the survey may have further contributed to

Page 23/30 
refusal of participation. Third, although the questionnaire was piloted and adjusted before adopting the final version, it was only available online, thus restricting the participation of CPs with little computer literacy and poor internet access. Fourth, since we did not have comparable data about burnout of CPs just prior to the pandemic, we were not able to evaluate any incremental effect of the COVID-19 pandemic on burnout. Finally, although taking into consideration of some potential confounders in the multivariable models, residual confounding is still possible. Further studies exploring the independent and combined effect of the economic crisis on the burnout of Lebanese CPs would be highly recommended in the future since the financial hardship was found also associated to higher level of burnout.

The level of burnout detected among Lebanese CPs is disquieting since it could reveal only the tip of the iceberg of the crisis in Lebanon. The closure of some pharmacies and the reduced operating hours reflected the burnout negative impacts that would not be restricted to CPs mental health and financial status but would also affect the patient care. Of note, preventing burnout is complicated as factors causing burnout in CPs can be unique to this career, more pervasive risk factors present in similar healthcare professions suggest an encompassing problem. However, to date, there were no tangible interventions and action taken by health organizations s to combat burnout that concentrated on healthcare worker burnout in Lebanon including CPs. Hence, it is important to address factors identified by our study that potentially contributing to burnout among CPs and to mitigate the long-term negative consequences. Some reported strategies including ideas and considerations of burnout prevention from compiled literature could be outlined to offer a framework to address burnout. This includes encouraging leadership qualities that facilitate staff wellbeing, decreasing workload, improving achievement of quality measures, choosing incentives wisely, and encouraging a work-life balance such as offering greater scheduling flexibility. In addition, encouraging peer support, building support systems through family, friends, and interdisciplinary teamwork collaboration can boost morale and reduce burnout.

\section{Conclusion}

Our study showed that burnout hits $81.9 \%$ of the Lebanese CPs and unveiled several risk factors significantly affecting burnout. In the context of economic collapse and politic turmoil, other individual confounding/interfering factors of the risk of burnout in pharmacists should be investigated. This alarming prevalence called health authorities to take prompt and warranted measures based on the factors associated with this syndrome unearthed in this study, to prevent burnout and mitigate among CPs in order to support resiliency in the profession. Prevention strategies and interventions on individual and organizational basis like focusing on worklife balance, minimizing the level of chronic stress, increasing work satisfaction, peer support, counseling and selfcare were needed.

\section{Declarations}

\section{Author Contributions:}

D.Y. was involved with study conception and design, data collection and analysis, drafted and revised the manuscript.

J.Y was involved with study conceptualization and design, drafting and revising the article. 
L.A.A and H.S were involved in the revision of the manuscript. All authors have read and approved the final version of the article.

\section{Funding:}

This research received no external funding.

\section{Acknowledgments:}

\section{The authors would like to thank all community pharmacists who accepted to be part of this study.}

\section{Informed Consent Statement:}

Informed consent for participating in the study was obtained digitally through Google Forms from all subjects, and all methods were carried out in accordance with the relevant guidelines and national regulations for the Nonclinical studies. Specifically, at the beginning of the questionnaire, participants were asked whether they agree to participate in the research in order to be included in the study. Participants were also informed that their participation was voluntary and that they had the right to leave at any time without providing any explanation. No incentives were provided to the study participants.

\section{Data Availability Statement:}

The datasets generated during the current study are not publicly available but are available from the corresponding author on reasonable request.

\section{Conflicts of Interest}

The authors declare that they have no competing interests and they have no known competing financial interests or personal relationships that could have appeared to influence the work reported in this paper.

\section{Consent for publication}

Not applicable.

\section{References}

1. Soler, J.K., et al., Burnout in European family doctors: the EGPRN study. Fam Pract, 2008. 25(4): p. 24565.

2. Poghosyan, L., L.H. Aiken, and D.M. Sloane, Factor structure of the Maslach burnout inventory: an analysis of data from large scale cross-sectional surveys of nurses from eight countries. Int J Nurs Stud, 2009. 
46(7): p. 894-902.

3. Hall, L.H., et al., Healthcare Staff Wellbeing, Burnout, and Patient Safety: A Systematic Review. PloS one, 2016. 11(7): p. e0159015-e0159015.

4. Bookwalter, C.M., Challenges in Community Pharmacy During COVID-19: The Perfect Storm for Personnel Burnout. US Pharm, 2021. 46(5): p. 28-31.

5. Sabater-Galindo, M., et al., Patients' expectations of the role of the community pharmacist: Development and testing of a conceptual model. Res Social Adm Pharm, 2017. 13(2): p. 313-320.

6. Magola, E., S.C. Willis, and E.I. Schafheutle, Community pharmacists at transition to independent practice: Isolated, unsupported, and stressed. Health Soc Care Community, 2018. 26(6): p. 849-859.

7. Hepler, C.D. and L.M. Strand, Opportunities and responsibilities in pharmaceutical care. American journal of hospital pharmacy, 1990. 47(3): p. 533-543.

8. Tice, B., Pharmacist Burnout: A Cry for a Transformative Approach to Traditional Pharmacy Practice. Pharmacy times, 2021.

9. Todd, A., et al., The positive pharmacy care law: an area-level analysis of the relationship between community pharmacy distribution, urbanity and social deprivation in England. BMJ open, 2014. 4(8): p. e005764.

10. Bach, A.T. and J.A. Goad, The role of community pharmacy-based vaccination in the USA: current practice and future directions. Integrated pharmacy research \& practice, 2015. 4: p. 67-77.

11. Durham, M.E., P.W. Bush, and A.M. Ball, Evidence of burnout in health-system pharmacists. American Journal of Health-System Pharmacy, 2018. 75(23_Supplement_4): p. S93-S100.

12. Jones, G.M., et al., Factors associated with burnout among US hospital clinical pharmacy practitioners: results of a nationwide pilot survey. Hospital pharmacy, 2017. 52(11): p. 742-751.

13. Dugani, S., et al., Prevalence and factors associated with burnout among frontline primary health care providers in low-and middle-income countries: a systematic review. Gates open research, 2018. 2.

14. Elbarazi, I., et al., Prevalence of and factors associated with burnout among health care professionals in Arab countries: a systematic review. BMC health services research, 2017. 17(1): p. 1-10.

15. West, C.P., L.N. Dyrbye, and T.D. Shanafelt, Physician burnout: contributors, consequences and solutions. J Intern Med, 2018. 283(6): p. 516-529.

16. Golkar, A., et al., The influence of work-related chronic stress on the regulation of emotion and on functional connectivity in the brain. PLoS One, 2014. 9(9): p. e104550.

17. Papathanasiou, I.V., Work-related Mental Consequences: Implications of Burnout on Mental Health Status Among Health Care Providers. Acta Inform Med, 2015. 23(1): p. 22-8.

18. Dyrbye, L.N., et al., Burnout and suicidal ideation among U.S. medical students. Ann Intern Med, 2008. 149(5): p. 334-41. 
19. Shanafelt, T.D., et al., Special report: suicidal ideation among American surgeons. Arch Surg, 2011. 146(1): p. 54-62.

20. Jones, G.M., et al., Factors Associated With Burnout Among US Hospital Clinical Pharmacy Practitioners: Results of a Nationwide Pilot Survey. Hosp Pharm, 2017. 52(11): p. 742-751.

21. McQuade, B.M., et al., Feeling the burn? A systematic review of burnout in pharmacists. Journal of the American College of Clinical Pharmacy, 2020. 3(3): p. 663-675.

22. Patel, S.K., et al., Prevalence and risk factors of burnout in community pharmacists. Journal of the American Pharmacists Association, 2021. 61(2): p. 145-150.

23. Nazar, H., et al., A systematic review of the role of community pharmacies in improving the transition from secondary to primary care. British journal of clinical pharmacology, 2015. 80(5): p. 936-948.

24. Blumenthal, D., et al., Covid-19-implications for the health care system. 2020, Mass Medical Soc.

25. Visacri, M.B., I.V. Figueiredo, and T. de Mendonça Lima, Role of pharmacist during the COVID-19 pandemic: a scoping review. Research in social and administrative pharmacy, 2021. 17(1): p. 1799-1806.

26. Khojah, H.M., et al., Exposure of community pharmacists to COVID-19: A multinational cross-sectional study. Journal of Taibah University Medical Sciences, 2021.

27. Hayden, J.C. and R. Parkin, The challenges of COVID-19 for community pharmacists and opportunities for the future. Irish journal of psychological medicine, 2020. 37(3): p. 198-203.

28. Yan, L., et al., The psychological impact of COVID-19 pandemic on health care workers: $A$ systematic review and meta-analysis. Frontiers in psychology, 2021. 12: p. 2382.

29. Abi-Rached, J. and I. Diwan, The Socioeconomic Impact of COVID-19 on Lebanon: A Crisis Within Crises. Published June 2020. 2020.

30. Visacri, M.B., I.V. Figueiredo, and T.d.M. Lima, Role of pharmacist during the COVID-19 pandemic: $A$ scoping review. Research in social \& administrative pharmacy : RSAP, 2021. 17(1): p. 1799-1806.

31. Austin, Z. and P. Gregory, Resilience in the time of pandemic: The experience of community pharmacists during COVID-19. Res Social Adm Pharm, 2021. 17(1): p. 1867-1875.

32. von Elm, E., et al., The Strengthening the Reporting of Observational Studies in Epidemiology (STROBE) statement: guidelines for reporting observational studies. PLoS Med, 2007. 4(10): p. e296.

33. Chong, M.-Y., et al., Psychological impact of severe acute respiratory syndrome on health workers in a tertiary hospital. The British journal of psychiatry, 2004. 185(2): p. 127-133.

34. Kristensen, T.S., et al., The Copenhagen Burnout Inventory: A new tool for the assessment of burnout. Work \& Stress, 2005. 19(3): p. 192-207.

35. Creedy, D., et al., Prevalence of burnout, depression, anxiety and stress in Australian midwives: a crosssectional survey. BMC pregnancy and childbirth, 2017. 17(1): p. 1-8. 
36. Choi, D.-a., et al., Descriptive Statistics and Visualizing Data, in Basic Quantitative Research Methods for Urban Planners. 2020, Routledge. p. 107-132.

37. Patel, S.K., et al., Prevalence and risk factors of burnout in community pharmacists. J Am Pharm Assoc (2003), 2021. 61(2): p. 145-150.

38. Jocic, D. and D. Krajnovic, State anxiety, stress and burnout syndrome among community pharmacists: relation with pharmacists' attitudes and beliefs. Indian Journal of Pharmaceutical Education and Research, 2014. 48(2): p. 9-15.

39. Almodaimegh, H., Prevalence of burnout among hospital pharmacists at National Guard Hospital in Riyadh, Saudi Arabia. 2020.

40. Lahoz, M.R. and H.L. Mason, Burnout among pharmacists. American pharmacy, 1990(8): p. $28-32$.

41. Protano, C., et al., A cross-sectional study on prevalence and predictors of burnout among a sample of pharmacists employed in pharmacies in central Italy. BioMed research international, 2019. 2019.

42. Balayssac, D., et al., Burnout, associated comorbidities and coping strategies in French community pharmacies-BOP study: a nationwide cross-sectional study. PloS one, 2017. 12(8): p. e0182956.

43. Rivera-Torres, P., R.A. Araque-Padilla, and M.J. Montero-Simó, Job stress across gender: the importance of emotional and intellectual demands and social support in women. International journal of environmental research and public health, 2013. 10(1): p. 375-389.

44. Calgan, Z., D. Aslan, and S. Yegenoglu, Community pharmacists' burnout levels and related factors: an example from Turkey. International journal of clinical pharmacy, 2011. 33(1): p. 92-100.

45. Chui, M.A. and D.A. Mott, Community pharmacists' subjective workload and perceived task performance: a human factors approach. Journal of the American Pharmacists Association, 2012. 52(6): p. e153-e160.

46. Gupchup, G., Burnout in a sample of HMO pharmacists using the Maslach Burnout Inventory. Journal of Managed Care Pharmacy, 1998. 4(5): p. 495-503.

47. Johnson, R.E., L.D. Ried, and N. Robertson, Self-reported burnout among HMO pharmacists. Journal of pharmaceutical marketing \& management, 1987. 2(2): p. 107-127.

48. Jackson, R.A., An Analysis of Burnout among School of Pharmacy Faculty. American Journal of Pharmaceutical Education, 1993. 57(1): p. 9-17.

49. El-lbiary, S.Y., L. Yam, and K.C. Lee, Assessment of burnout and associated risk factors among pharmacy practice faculty in the United States. American journal of pharmaceutical education, 2017. 81(4).

50. Gaither, C.A. and A. Nadkarni, Interpersonal interactions, job demands and work-related outcomes in pharmacy. International journal of pharmacy practice, 2012. 20(2): p. 80-89.

51. Chui, M.A., K.A. Look, and D.A. Mott, The association of subjective workload dimensions on quality of care and pharmacist quality of work life. Research in Social and Administrative Pharmacy, 2014. 10(2): p. 328- 
52. Shanafelt, T.D., Enhancing meaning in work: a prescription for preventing physician burnout and promoting patient-centered care. Jama, 2009. 302(12): p. 1338-1340.

53. Söderström, M., et al., Sleep and sleepiness in young individuals with high burnout scores. Sleep, 2004. 27(7): p. 1369-1377.

\section{Figures}

\section{COVID-19 threat as perceived by community pharmacists}

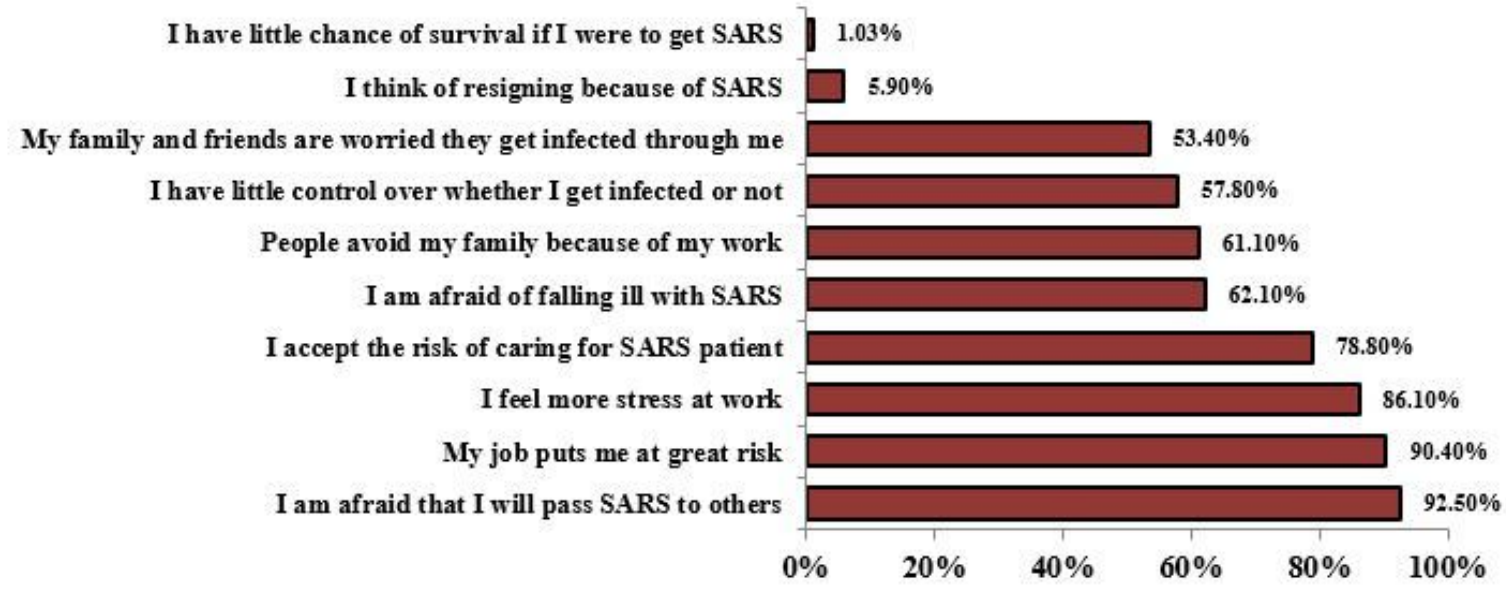

Figure 1

Community pharmacists' perception of COVID-19 threat

\section{Prevalence of burnout among Lebanese community pharmacists}

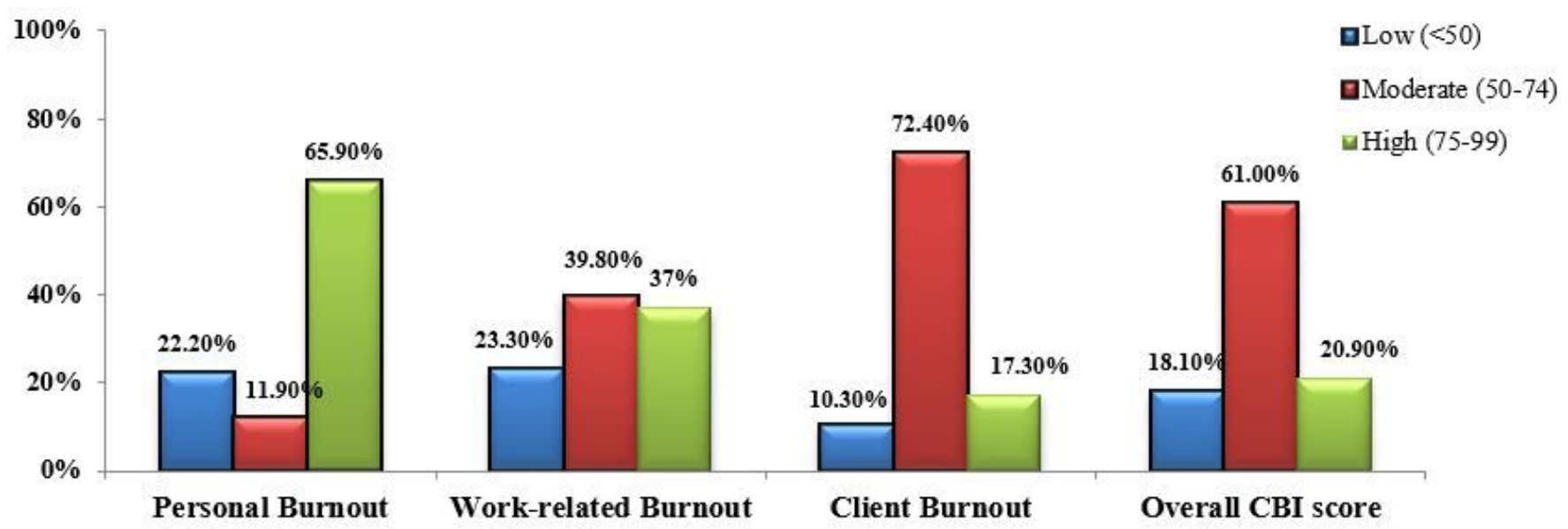


Prevalence of burnout among Lebanese community pharmacists

Page $30 / 30$ 